\title{
Personal Agency Inspired by Hardship: Bilingual Latinas as Liberatory Educators
}

\author{
Amanda R. Morales \\ University of Nebraska-Lincoln \\ U. S. A. \\ M. Gail Shroyer \\ Kansas State University \\ U.S. A.
}

\begin{abstract}
This qualitative multiple case study focused on eleven nontraditional, bilingual, Latinas within a teacher education program. The study explored various factors that influenced participants' desire to pursue and ability to persist as pre-service teachers. The overarching theme identified among participant discourse was personal agency inspired by hardship. Findings indicated that, as a result of their cultural and experiential understandings, participants enacted culturally responsive teaching with their Latino/a students. Furthermore, participants demonstrated a strong sense of personal agency to improve the educational outcomes of culturally and linguistically diverse students and a desire to advocate specifically on behalf of English learner Latinola students.
\end{abstract}

KEYWORDS: Latinola education, critical race theory, teachers of color, paraeducators, recruitment \& retention

\author{
Rationale for Study \\ Conceptual Framework \\ Context and Participants \\ Methods and Analysis \\ Findings \\ Implications and Recommendations \\ Notes \\ References \\ Author Contact
}

Latino/a, English Learner (EL) students' identity, self-worth, cultural consciousness, and life aspirations are shaped within the often daunting social and political context of U.S. schools (Herrera, 2016; Katz \& DaSilva Iddings, 2009). How they and their families are viewed and treated by the dominant culture and how educational institutions guide them has a significant impact on their educational choices and outcomes (Kanno \& Grosik, 2012). 
Critical educators believe that students have a right to experience schools that validate, challenge, and inspire them to utilize their cultural and experiential knowledge to understand new content and contexts (Johnson \& Williams, 2015; Walqui \& van Leir, 2010). An emancipatory education is one that honors and nurtures students' individual ways of knowing through ongoing dialog and provides opportunities for students to make connections between their own personal situations and struggles and those within the larger society (Maramba \& Velasquez, 2012; Morales, 2016). More specifically, this type of education serves as a vehicle for self-actualization and upward mobility. Ultimately, an emancipatory education empowers students to redefine themselves and the groups they represent in educational and social spheres and gives them language to challenge deficit perspectives that others might have toward these groups (Maramba \& Velasquez, 2012; Rodríguez \& Oseguera, 2015). While such empowering educational experiences tend to be rare for Latino/a students within our current educational system, there are those who succeed and persist in education despite odds (Delgado Bernal, Burciaga, \& Flores Carmona, 2015).

\section{Rationale for the Study}

Latino/a English Learners who desire to gain a college degree have a complex task before them as they struggle to navigate the historical, cultural, and institutional barriers on their pathway to the baccalaureate (Delgado Bernal, Burciaga, \& Flores Carmona, 2012). Ideally U.S. education systems are intended to be places of equal opportunity for all children; however, underlying vestiges of racism based on hegemonic perspectives continue to shape policy and practice regarding culturally and linguistically diverse (CLD) students (Holmes, Fanning, Morales, Espinoza, \& Herrera, 2012). These barriers have an established history-rooted in remnants of racism, sexism, and classism. Still today, voices and perspectives of diverse populations are frequently lost within mainstream social, governmental, and educational institutions (Kohli \& Solórzano, 2012; Macedo, 2006). The effects of such can be seen in the academic achievement of Latino students at every level (Fry \& Parker, 2012; Rodríguez \& Oseguera, 2015). While the National Center for Educational Statistics reports that Hispanic students graduated at a rate of $71 \%$ in 2010 , this is quite low when compared to $83 \%$ of Whites (2010). Even more concerning, in a recent study conducted by the ACT and Excelencia in Education, nearly half of the 2014 ACT-tested Latino/a high school graduates met none of the four ACT College Readiness Benchmarks (ACT, 2015). Clearly, such realities directly impact the demographic makeup of college campuses as well as the workforce.

Latino/a students who endure odds at the K-12 level and successfully enroll in college often report unique factors within their family, culture, community, or school that had a protective effect on them and fostered personal resilience (Benard, 1991, 2004; Bordes-Edgar, Arredondo, Robinson-Kurpius, \& Rund, 2011; Morales, 2011). This resiliency is critical to survival in institutions of 
higher education, which tend to be steeped in Eurocentric traditions and hegemonic social constructs (Irizarry, 2011). Latino/a students' often-poor integration and resulting attrition from college helps explain why, as of 2011, "only 21 percent of Latino adults 25 and over had earned an associate degree or higher, compared to 40 percent of all adults" (Santiago, \& Lopez, 2013, p. 7).

While resilient Latino/as do go on to pursue college degrees, frequently the process, context, and timeline by which they complete look quite different from that of White traditional students (Crisp, Taggart, \& Nora, 2015; Morales, 2011). Once in college, Latinas ${ }^{1}$ in particular, for a wide range of social, cultural, and economic reasons, often do not achieve their academic goals along traditional pathways and timeframes (Crisp et al., 2015). For example, a growing number of Latina students are enrolling in college as non-traditional students after working as service laborers or caregivers for a period of time (Rueda, Monzó, \& Higareda, 2004). While many female students commonly perform the juggling act of managing family, work, and school responsibilities, research suggests that these non-traditional experiences are what drive Latinas to endure hardships in pursuit of a better future (Shroyer, Yahnke, Morales, Dunn, Lohfink, \& Espinoza, 2009; Simoniello, 1981).

Many bilingual Latinas find viable employment as paraeducators (language support or resource staff members) in schools within their communities (Villegas \& Clewell, 1998). As they begin college, they are able to earn the credits necessary to qualify for paraeducator positions in schools where the demand for bilingualism is high (Lohfink, Morales, Shroyer, \& Yahnke, 2012). As they learn the K-12 system and become connected, their value within the school increases (Monzó \& Rueda, 2001). The literature supports the premise that their common experiences as struggling CLD students in school, and as women who show leadership within the home and their cultural community, provide them with sociocultural expertise (Ernst-Slavitt \& Wenger, 2006; Lucero, 2010; Rueda et al., 2004; Villegas \& Clewell, 1998). As a result, these bilingual paraeducators are critical assets to schools as they serve as cultural brokers for the increasing number of CLD children and families within their districts (Genzuk \& Baca, 1998; Ernst-Slavitt \& Wenger, 2006). Some argue that, due to Latina, EL, non-traditional students' common struggles with language, acculturation, socialization, and education, they are often able to relate to Latino/a, EL students in ways White, monolingual teachers cannot (Goldenberg, 2014; Lucero, 2010; Monzó \& Rueda, 2001).

In fact, the very factors that make CLD non-traditional students effective are what also make them difficult to retain and graduate (Rueda, Genzuk, Baca, \& Hentschke, 1999). Sound practices for recruitment and retention of EL Latino/as have been established in the literature (Herrera, Morales, Holmes, \& Herrera Terry, 2011) as well as strategies for effectively supporting nontraditional students in college (Genzuk \& Baca, 1998; Genzuk \& French, 2002; Lohfink et al., 2012); however, more research is needed to determine the various factors that foster resiliency among college students who are both Latino/a and non-traditional. Furthermore, research in teacher preparation has given little 
attention to identifying the key factors that influence Latino/a paraeducators, in particular, to pursue a teaching degree or that drive them to persist despite the odds (Ernst-Slavitt, \& Wenger, 2006; Romo, 2005). Therefore, researchers in this study sought to address this identified gap in the literature in hopes to increase institutions' awareness of common experiences among EL Latinas in education as well as the value that this non-traditional population has as an untapped pool of potential teachers. Furthermore, this work provides considerations for teacher preparation programs as they design programming to effectively recruit, retain and graduate CLD teachers.

\section{Conceptual Framework}

To explore fully the influential experiences and critical incidents that have defined the varied paths Latina, EL, non-traditional students take to become teachers, the researchers utilized a blended theoretical framework based on established literature in the areas of resiliency, Critical Theory, Critical Race Theory (CRT), and Latino Critical Race Theory (LatCrit). They approached the data with two phases of analysis: first, using a structured analysis based on the categories established in Benard's resiliency framework (2004), and second, using a thematic analysis (via open coding) of emergent themes informed by Critical Theory, CRT, and LatCrit theory. This article focuses specifically on findings from the second phase of analysis as it illuminates the role that language and culture play in the development of effective teachers for EL Latino/a students.

Each of Critical Theory, CRT, and LatCrit addresses unique aspects of the historical, political, societal, and educational experiences of oppressed and marginalized populations in the United States. However, all three rest upon a similar philosophical paradigm, which actively challenges established systems and institutions as well as "Americanized" notions of democracy, ethics, meritocracy, and equality (Howard \& Navarro, 2016). Critical Theory emphasizes the generative power of language and voice as a social force (Giroux \& McLaren, 1992; Wink, 2005). This force can define/redefine reality and accepted truth, and can be used to both liberate and to oppress. Critical Race Theory (with its origins in formal law) addresses legal and political constructs that have defined race and class historically in this country and works to deconstruct systems of racism, classism, and sexism that impact the everyday experiences of people of color (Bell, 1989; Delgado \& Stefancic, 2001). In the realm of education, theorists utilize CRT to examine how these systems of oppression shape policy and practice within schools and ultimately limit access and success for women and children of color in schools.

LatCrit focuses more specifically on the complex issues that result from racism that targets the culture, language, and immigrant status of Latino/as in this country (Delgado Bernal, 2002; Solórzano \& Delgado Bernal, 2001). Furthermore, LatCrit provides the theoretical basis for considering how these 
discriminatory factors impact the social, psychological, and educational development of CLD individuals within an educational system (K-16 and beyond) that is based on dominant Eurocentric ideologies (Delgado Bernal, 2002).

While the areas of Critical Theory, CRT, and LatCrit provide the language and context to discuss and deconstruct the realities faced by subjugated populations in our society, they also provide a counternarrative to dominant, "deficit" discourses used to describe people of color. This counternarrative elucidates and validates the lived experiences and rich assets of oppressed peoples. With these theories providing a framework for the study, this paper illustrates ways in which eleven non-traditional EL Latinas negotiated larger social, historical, economic, and cultural factors impacting their resiliency and persistence as pre-service teachers.

\section{Context and Participants}

The researchers crafted a multiple case study design utilizing a purposive sample of Latina, EL, non-traditional students. These students were involved in a unique, distance-delivered, $2+2$, elementary education program offered by a land grant university in partnership with three districts and two community colleges in a Mexican minority-majority area of a mid-western state. This "grow your own teacher" program, called AccessUS, prepared 20 first-generation college females already associated with partnering school districts, primarily as paraprofessionals, to become teachers. The "grow your own teacher" education program was offered as part of a larger K-16 simultaneous renewal grant through the Department of Education called the Equity \& Access Partnership. The overarching grant served as the support structure for AccessUS as it provided human resources needed to sustain the program. Twelve students within the cohort of 20 were Latina, EL, non-traditional students. These twelve women were ideal candidates for the study, as they possessed all the characteristics of interest (Latino/a, bilingual, first-generation, non-traditional students). Ultimately, eleven of the twelve Latina AccessUS students agreed to participate in this study.

While these women had many of the same key characteristics, their background experiences varied widely. Of the eleven Latinas who elected to participate, four students came to the United States as immigrants. Three of the four students moved to the States as children and one moved to the States as an adult. Six of the eleven were first-generation U.S. natives, and one was a second- generation native. In regards to schooling, seven of the eleven began attending U.S. public school in kindergarten, one in pre-kindergarten, one in $5^{\text {th }}$ grade, and one in college. The final participant was a transnational student, who entered U.S. public school and then left numerous times during her K-12 years. Four of the eleven Latinas were placed in ESOL pullout programs, seven were in English-only immersion programs, and none had been placed in a bilingual program upon entering school in the United States. At the time of the study, all 
eleven women were fluent in Spanish and English (both spoken and written), and all were identified as non-traditional students due to age, marital and/or parental status, or financial independence, as defined by university guidelines. Their ages at the time of the study ranged from 22 to 47 with the average age being 31 . Of the eleven women, eight were married, nine had children, and two were single parents.

\section{Methods and Analysis}

As this was a multiple case study, each of the eleven participants was initially studied as an individual. Within each case, the researchers fully took into account how each participant's characteristics and experiences shaped her identity and her narrative. Being mindful of the great potential for variance among Latino/as from differing immigration and educational experiences (MatuteBianchi, 1991), each case was approached with the intent to understand those themes most salient to the individual. However, despite variance in experiences across these eleven cases, at the time of the study each participant had spent approximately ten years in the same region of the state, being socialized as majority-minority Latino/as in a semi-rural, agrarian community. It was when we looked across cases that we were surprised by the similarities they demonstrated and the themes that cut across each case as language minority individuals. These cross-cutting themes-with connections to the literature and important implications for $\mathrm{K}-12$ as well as college and university policy makers, administrators, and teachers-provide the focus for this article.

According to Bogdan and Taylor (1975), it is through stories that "the important events and experiences in a person's life are told in ways that capture the person's own feelings, views, and perspective" (p. 12). Therefore, for the purposes of this study, the researchers engaged in a qualitative, multiple case study. This approach allowed for the rich interpretation of participant perceptions and experiences shared through individual and collective stories (Creswell, 2007).

The researchers allowed the following questions to guide the development of tools and methods for the study:

1. What internal characteristics and external factors foster Latina, EL, non-traditional student resiliency in reaching and remaining in college?

2. In what ways do these characteristics and factors influence participants' desire to pursue and ability to persist in teacher education?

To these ends, a variety of qualitative methods for the collection and analysis (categorical aggregation, open coding) of data were employed over a three-year period. The two primary sources of data were an open-ended survey and semi-structured interviews. These primary sources were supplemented with 
artifacts from courses and program requirements. All data collection strategies were approved by the university's Institutional Review Board to ensure adherence to ethical standards and rights to human subjects.

The first primary source was an open-ended autobiographical survey (Dillman, 2000), designed and administered primarily to gain demographic and historical information on the students and their families. This survey was first piloted with a convenience sample of five Latina on-campus students prior to use in this study. The second primary source of data was individual, in-depth, semistructured interviews (each approximately two hours in length) using a tool based on the literature and initial information gathered from the open-ended survey. Follow-up interviews were conducted via phone and email over the two months following the formal interviews (Bogdan \& Biklen, 1992; Creswell, 2007). These two primary sources were triangulated with secondary pre-existing course and program artifacts such as cultural family narratives and journal entries.

Primary and secondary data were analyzed within individual case studies using open coding of emergent themes informed by the literature. A cross-case analysis of all eleven case studies was then completed. The findings below are based on themes identified in the cross case-analysis representing at least eight of the eleven individual case studies and all data sources.

\section{Findings}

When considering the ways in which participants' internal characteristics and external factors influence their desire to pursue and ability to persist in teacher education (a merger of both study questions), the researchers identified one overarching theme. The theme personal agency inspired by hardship was found evident among data from all eleven women in this study. The term agency in this study, a concept developed in previous literature (Delgado Bernal, 2002; Maldonado, Rhoads, \& Buenavista, 2005; Varghese, 2012) is used to describe participants' sense of self-efficacy, autonomy, and power to impact change for themselves and others in their schools and communities. Hardships are the personal struggles these eleven women faced, and continue to face, in familial, educational and professional contexts. The theme of agency inspired by hardship directly relates to the complex interplay of internal and external forces that shaped who they are as culturally and linguistically diverse women and the strengths they developed during their time in the elementary education program.

When reflecting on their own experiences in schools, both the past via their childhood experiences as students and at the time of this study as student teachers, ten of the eleven participants spoke from a clear social justice perspective, meaning they sought to address unjust policies and practices they had witnessed within schools. As the data below will demonstrate, participants shared multiple ways in which they wanted to improve the educational outcomes for Latino/as and ELs in particular. As evidenced in their narratives, participant 
experiences (both positive and negative) as Latina, ELs served as the driving force behind their desire to impact educational change for other CLD students.

Within this overarching theme of agency inspired by hardship, the researchers identified six sub-themes found among the data in this study (see Table 1). Each of these sub-themes was identified in at least eight of the eleven individual case studies.

Table 1

Sub-Themes Related to Agency Inspired by Hardship

"Ganas" (the burning desire \& determination to overcome, despite acute adversity) (from eleven individual cases)

Racism and marginalization (from eleven individual cases)

Language as power (from ten individual cases)

Culturally relevant teaching = effective teaching (from ten individual cases)

Agency as teachers - racial uplift (from ten individual cases)

Cultural duality - a borderlands existence (from eight individual cases)

This article highlights three of the six sub-themes found from cross-case analysis. Using excerpts of participant voice, the authors will illustrate how each of these three sub-themes relates to the overarching theme of personal agency inspired by hardship.

\section{Language as Power}

The sub-theme of language as power found among the Latinas' voices relates to the unique power of language (for better or worse) to define identity and determine value for the Latinas in this study. Nine of the eleven participants expressed low self-esteem or uncertainty regarding their abilities in school, particularly related to successful use of the English language. Participants shared how in their K-12 years they were chastised and/or punished for speaking Spanish inside and outside the classroom. One student, Yolanda, stated that she and her other Mexican classmates constantly were told, "You can't speak Spanish," even at lunch or at recess. She said, no matter the context, "We'd get in trouble for speaking [Spanish]." (survey)

Another student, Aurelia, described the difficult transition she experienced related to language when entering U.S. schools at age six. She said that while 
she received ESOL support in the way of a pullout program for three years, she hated it because they were not allowed to speak Spanish even though all the students were Spanish speakers. Aurelia's quote below illustrates the isolation and disillusionment often experienced by the participants when entering U.S. schools.

I would feel frustrated and alienated from everyone else. I would hide on the playground and cry through recess because I could not associate with anybody else.... I was frustrated because I could not ask questions! I pointed to things I did not understand.... (survey)

As was the experience for Aurelia, three other participants indicated that when their first experiences in school were negative, threatening, or damaging, they disengaged and lost confidence as learners.

Ironically, once they gained adequate skills in English, the participants' ability to speak Spanish often placed them in the tenuous position of language brokering in schools. One student, Beti, described how one moment she was getting in trouble for asking another Spanish-speaking student a question and the next minute she was being called to the office to serve as an interpreter for the principal. She said, "When they needed a translator...this was the time when they would praise me and say positive words about my language" (interview).

Another student, Alejandra, mentioned frequently interpreting for Spanishspeaking parents who came to the school and how she struggled staying caught up in her coursework because she was always being pulled out of the classroom. She said, "In $6^{\text {th }}$ grade I was already interpreting. I would get sent to the office to help.... was excluded from important content that I should have learned" (survey). As this participant described her lack of consistent academic support as an EL, she articulated the impact of not having dual language teachers or paraeducators in the classroom. "It just took so long for me to learn because none of my ESL teachers spoke Spanish and in my classes there was never a Spanish speaking person in the classroom" (survey). Many of the participants indicated that through their college coursework, they fully realized the importance of not only dual language support but also consistent validation of students' native language and culture in instructional settings.

Despite many "English only" rules in the classrooms, participants indicated that they were willing and able to support students' learning and language development by making connections between concepts in their students' native language and English. One participant, Sophia, lamented over lost opportunities for EL students due to damaging language policies by saying, "I always think about how much kids miss because they're really bright and they know the ideas, but they [ELs] don't know that they know them because they don't know them in English" (survey). She demonstrated her agency by indirectly challenging current school policies and procedures for working with EL students. Sophia indicated that her ability to speak Spanish and make critical connections for her students during instruction was a definite "plus" in the classroom. The power of language proved salient for ten of the eleven participants, as their difficulties as ELs 
inspired a sense of responsibility to advocate for their students facing similar language challenges.

\section{Culturally Responsive Teaching = Effective Teaching}

Within this study, the term culturally responsive teaching is based on a blend of definitions established in prior research (Gay, 2000; Ladson Billings, 1995, Villegas \& Lucas, 2002). The sub-theme of culturally responsive teaching as a component of effective teaching is defined in this study as the participants' intuitive and learned understandings of how to support Latino/a, EL students comprehensively in the classroom. Data indicated a patience and willingness to support diverse students as a result of understanding their backgrounds. Ten of the eleven participants described culturally responsive teaching practices they used to more effectively meet the needs of their culturally diverse students. All but one participant discussed ways in which they used linguistic, cultural, and experiential knowledge to effectively teach their Latino/a students. These teaching practices were inspired by their own personal and academic experiences.

Janie's narrative below demonstrates her frustration with teachers' general and low expectations for their Latino/a students as well as how she has learned to enact mindfulness and teach in culturally responsive ways.

I want to be a teacher not just to teach content. I want to...help them from where they are [to] where they can go next... and that's what I think some teachers [don't do]...they might know the content, but if they don't have a heart to see that there's a student that's struggling or...a lot of [teachers] don't know the family....

I do home visits as a family liaison... if only the teachers knew what these kids are going through... could they be a little bit compassionate? There're some teachers [that say], "Oh well they have three strikes and they're out." It's like, how can you give a kid three strikes? Don't give up on them, you know? It's frustrating because I think that's many of our kids. I see that a lot, especially with our Latino males at the middle school. It's sad and then I tell myself, "but then we wonder why we have this gang issue".... Because that's who is there [for them], you know. They don't have anybody else. Nobody cares. (interview)

Like others, Janie frequently witnessed teachers' negative attitudes towards and lack of confidence in Latino/a students. But once again, the hardships personally experienced by the participants inspired them to become advocates for culturally responsive teaching to effectively help their students deal with challenges in the learning environment. Similarly, the youngest participant in the study, Alejandra, shared the various ways she effectively taught and supported Latino/a, EL students in her classroom. She described an instance where she was able to 
incorporate not only students' native language but also their cultural and experiential funds of knowledge to effectively teach a concept.

When I was there with my class [during student teaching], our students scored so high, they did so well and I think I helped them a lot. Like one day we were talking about wheat and they didn't know what wheat was and I told one of my students. She then knew what wheat was and she said, "We have some at my house!" I said, "You do? Can you bring some tomorrow?" and she said, "Yeah." And so the next day for show and tell, I told my Spanish-speaking students this is what wheat is and they've seen it before.... "Oh it's el trigo!"... "Yeah, that's the English word...Wheat." and they said, "Oh!" and so it clicks and they realize they already know. (interview)

In this case, through the use of their native language and lived experience, students were able to connect their prior knowledge to new vocabulary and concepts. By challenging English only policies, by being mindful of students' experiences outside of the classroom, and by validating those experiences within their communications with students, participants were able to engage in culturally responsive teaching.

Aurelia, one of two participants who were involved in gang activity in their youth, further indicated that effective teaching involves more than just knowing the content and the language. Aurelia clarified that in order to make a difference for struggling Latino/a students, in particular, teachers must make personal connections and demonstrate that they care, as seen in this detailed excerpt:

I know all that background for a reason. [I] can personally connect and I don't see that [in school]. So, I think in a sense, that's what teaching is about. It's not just on the content part, but you have to know how to reach kids on that level. How to say, "Hey Juanita, how are you? How's your mom?... How are her hands?" Because a lot of our kids, their parents [work in] the packing plants. So you've got to know how to reach them.... "Did your dad find a job?" You know, because of the papers, the legal system. "Are you guys doing okay?"... We don't have teachers asking that because they don't understand. You know, [students say] "No my dad doesn't have papers to be here. They might take him away someday." You know, what are you going to say, "Let's just hope not!" and move on?

No, you know, if the kid is telling you [that], they're sharing a piece of them. How can you touch that, you know? "No mijo, you know, he needs to keep looking. Tell your mom to go to these places to find things...." I know where to get food; I know where to get second hand clothes, you know, because I've been there. "Tell them I said that you need to go to this one [thrift shop]. Shop on Monday, Wednesday, Friday.... If you're very desperate, go to that one, but go before 10 o'clock...". (interview)

As this excerpt illustrates, due to connections within the community and her own hardships, Aurelia possessed knowledge of students' families and knowledge of avenues for accessing resources that proved highly beneficial in connecting with 
and supporting her students. Throughout her interview Aurelia emphasized that cultural connections, high expectations, and authentic caring were the most critical elements for Latino/a student success. Similar to most of the other participants, her personal experiences led to culturally responsive teaching practices. It was through these demonstrations of care and personal connections that Aurelia consistently was able to build trust with her students and effectively engage those students on whom many teachers within her school had given up.

\section{Agency as Teachers for Racial Uplift}

As indicated, several of the participants felt a desire and a responsibility specifically to help Latino/a and EL students inside and outside the classroom. The final sub-theme to be presented, teacher agency for racial uplift, is used to describe participants' development of self-efficacy and confidence to advocate for themselves as well as their Latino/a and EL students. The data indicated that 10 of the eleven participants came to a realization during their educational program that they had not only the knowledge but also the power as educators to impact change in policy and practice. This commitment to racial uplift was strongly impacted by the hardships these 10 participants faced in their own educational experiences. For example, Janie related how gaining an education made her more confident to speak out on behalf of EL students.

[The] ESL program.... The way they deal with ESL students and newcomer students, it's not to where it should be. They're very... they don't give the services [that students] need, you know? And so I think it's helped me voice my opinion more and say, "No," you know, "This isn't right," ... but I don't think it's caused conflict. I think it made people open their eyes. Just like, I'm not this quiet little girl anymore. (interview)

As illustrated by the above quote, the researchers witnessed a shift in Janie's identity towards the end of her program. As a shy and unsure student initially, Janie became much more assertive in challenging deficiencies within the school. This developing sense of confidence was somewhat surprising, yet empowering for Janie, as evidenced in her narratives.

Similarly, Alejandra described an instance where EL students were being assessed in Spanish incorrectly based on regional linguistic variation, and she was able to determine errors and report it to her administrator. She shared her frustration with the situation and the teachers administrating the exam in this way:

So...they [the students] would get it wrong and that's why their score was low because of how they have it [on the test]....They're assuming they don't know it.... They just think, "Oh they're low, they don't know." Yeah, there are some [teachers] that say, "Oh well, I'm ESL-endorsed and I know Spanish; I could read this in Spanish...." But if you're not going to read it right, then what help are [you]? I mean, I understand we do need 
ESL people.... [To] at least know some does help, but I think that's why we need Latino/as to be teachers because I know that would be a big help. (interview)

As this quote suggests, Alejandra felt that Latino/a, EL students benefit more from having teachers who are from the same culture because they often understand local or regional nuances within the Spanish language. Her understanding of the Spanish language helped her to identify the problem. Furthermore, her willingness to speak up regarding the problem and to push to get it corrected demonstrated her personal agency on behalf of Latino/a students at the school.

Beti, another participant, voiced her concern about how her school was failing their Latino/a students. She indicated that teachers' inability to relate to diverse students served as a major hindrance to Latino/a student persistence overall. She said,

There's many students not graduating or they're dropping out, especially Hispanics or you know, diverse students. You mainly have white teachers that Hispanic/ Latino students do not relate to and they don't see themselves as being someone else. But when you have someone that can speak their language or that at least can relate to what they're going through, that pushes those students and they open up to you in a way that they are willing to try. (interview)

Beti went on to describe how she wanted to be the one to show students "how to be successful" in not only school but also life. As a student who struggled with self-doubt and experienced limited academic success as an EL prior to college, she had a strong desire to go back to her childhood community upon graduation in order to improve the educational outcomes for Latino/a students in her rural school.

Additionally, participants frequently referenced being a positive example for Latino/a students. The notion of providing students with opportunities to see themselves in professional positions of authority also was considered of great importance to many participants. Yolanda stated that she wanted to give back by helping other Latino/a students the way some of her teachers helped her. She said,

All the teachers I looked up to and felt most comfortable with were minority teachers. My belief has always been to give back to students what I was once given, that is, a love for education. To believe in themselves, and to [have] a safe classroom where they are challenged to do their best. (survey)

As these above quotes demonstrate, participants felt strongly about advocating for and supporting the Latino/a students in their classrooms. As Yolanda described, participants planned to demonstrate their support by creating environments where their students experience high expectations as well as high levels of encouragement. Through their stories described above, the Latinas in 
this study recount their experiences that impacted their resiliency and persistence as students and as teachers.

\section{Discussion and Conclusion}

Based on the selected findings described above, the researchers argue that (a) due to their unique and often difficult experiences as EL, Latinas, participants could relate to their EL, Latino/a students in authentic ways; (b) participants were culturally responsive as they utilized their culture, language, and experience to effectively teach their EL, Latino/a students; and (c) through a wide range of personal, social, and educational experiences participants developed a sense of personal agency to advocate for themselves and other Latino/as in their schools and communities.

Firstly, because these Latinas come from similar cultural backgrounds and have endured many of the same challenges, it was easier for them to empathize and to understand what EL students need but typically do not receive in schools. Similar to funds of knowledge, articulated by Moll, Amanti, Neff, and Gonzalez (1992), these non-traditional students approached their teaching of Latino/as with an enriched skill set, and as a result, they were better posed to build effective learning communities through authentic connections within their predominantly Latino/a populated schools.

Secondly, similar to Stanton Salazar's notions of cultural and social capital (2001), the researchers further concluded that participants' cultural and experiential understandings fostered not only empathy towards EL Latino/a students but also a heightened awareness and sensibility for how best to help them succeed. This described sensibility, coupled with participants' learning from coursework, resulted in culturally responsive teaching practices with their Latino/a students. Participants shared numerous examples of how they utilized common concepts, stories, or experiences from students' backgrounds to make meaningful connections. Additionally, participants gave accounts of how they used students' native language to clarify and elaborate on concepts when needed and the significant impact that minor language accommodations had on student understanding. Participants shared specific instances of how they were able to increase test scores for Latino/as in their classrooms when other teachers were unsuccessful. This finding supports and validates existing literature regarding the importance of native language support for comprehension among EL students (Collier \& Thomas, 2004; Rueda et al., 2004). By actively engaging their cultural ways of knowing and utilizing their native language, participants were able to increase their effectiveness in working with EL Latino/a students.

Thirdly, findings indicated that participants' various experiences served as catalysts for the development of personal agency among participants. Once again, the term agency is used to describe participants' sense of self-efficacy, autonomy, and power to impact change for themselves and other Latino/as in 
their schools and communities (Delgado Bernal, 2002; Maldonado et al., 2005). As these women neared the end of their educational program, they were able to reflect on the behaviors and attitudes they witnessed towards Latino/a students in schools. Similar to CLD students in other prior studies (Sleeter \& Thao, 2007; Valenzuela, 1999), these Latinas spoke passionately about the damaging effects of the culturally subtractive practices they saw at the systemic level and the extreme need for change (Howard \& Navarro, 2016). From a critical perspective, participants sought to combat the low-expectations and deficit perspectives that many teachers held toward Latino/a students and to shift the climate of schools from environments that devalue CLD students to environments that validate and support them (Delgado Bernal, 2002; Herrera et al., 2011; Nieto \& Bode, 2008).

Lastly, participants demonstrated a commitment to being role models and advocates for Latino/a students. In many cases this commitment translated into leadership on the part of these women. This sense of personal agency seen among participants echoes the findings from similar but limited studies done with historically oppressed populations in education. The characteristics of selfempowerment, advocacy, and racial uplift are the most evident outcomes of participant experience in this study (Apple, 1995; Darder, Baltodano, \& Torres, 2003; Giroux, 2001; Woodson, 1933; Robnett, 1997).

\section{Implications and Recommendations}

In light of the various themes and conclusions drawn, this study has implications for K-12 policy makers, administrators, and teachers as well as for colleges and universities as they consider ways to improve the recruitment, retention, preparation, and graduation of Latino/a students. Overall, findings point to a critical need for systemic change in perceptions, policies, and practices related to our EL Latino/a students in schools.

Study findings support existing literature that, in order to increase effectiveness with EL Latinas, schools must develop a more contextualized perspective of culturally and linguistically diverse learners at all levels within the K-16 system (Monzó \& Rueda, 2001). The findings also indicate that policy related to EL instruction and native language use (primarily for content understanding) in the classroom must be challenged. Policy makers must address the growing body of literature that points to bilingual and dual language programs as being highly effective for EL student success (Garcia, 2011).

At the administrative level, district leaders who are committed to increasing the learning outcomes of Latino/as should demonstrate this commitment through more inclusive hiring practices and their teacher development. Given the relatively remote location in which this study was conducted, the findings suggest that considerations for career ladder and "grow your own teacher" programs should be seriously deliberated. Findings indicated that these women, who lived and worked primarily as bilingual paraeducators in 
this region for a number of years, were ideal candidates for teacher education. As permanent residents in this majority Latino/a region of the state, the participants understood the backgrounds of students in the schools and were committed to staying in these communities upon graduation. This conclusion supports existing literature that points to the paraeducator pool for fulfilling ongoing teacher shortages in hard-to-staff regions of the country (Achinstein, Ogawa, Sexton, \& Freitas, 2010; Genzuk, Lavadenz, \& Krashen, 1994; Rueda et al., 2004). While effective strategies for recruiting and retaining this population may differ from traditional models, evidence suggests that teacher preparation programs, and ultimately K-12 schools, could benefit greatly from such efforts.

\section{Notes}

1. The term Latina is used to describe females whose heritage is rooted in Latin America (Mexico, Central, and South American countries). The term Latino/a is preferred over the term Hispanic, as Hispanic validates the Spanish colonization and the subjugation of indigenous cultures and languages in these regions.

\section{References}

Achinstein, B., Ogawa, R. T., Sexton, D., \& Freitas, C. (2010). Retaining teachers of color: A pressing problem and a potential strategy for "hard-to-staff" schools. Review of Educational Research, 80, 71-107.

American College Testing (ACT). (2015). Hispanic students lag behind their peers in college readiness: ACT and Excelencia report reveals mixed progress across subject areas. Washington, DC: Author. Retrieved from www.EdExcelencia.org/research

Apple, M. W. (1995). Cultural capital and official knowledge. In M. Berube \& C. Nelson (Eds.), Higher education under fire (pp. 91-106). New York, NY: Routledge.

Bell, D. (1989). And we are not saved: The elusive quest for racial justice. New York, NY: Basic Books.

Benard, B. (1991). Fostering resiliency in kids: Protective factors in the family, school, and community. San Francisco, CA: Far West Laboratory for Educational Research and Development. (ERIC Document Reproduction Service No. ED 335781)

Benard, B. (2004). Resiliency: What we have learned. San Francisco, CA: WestEd.

Bogdan, R. C., \& Biklen, S. K. (1992). Qualitative research for education: An introduction to theory and methods. Boston, MA: Allyn \& Bacon. 
Bogdan, R. C., \& Taylor, S. J. (1975). Introduction to qualitative research methods: A phenomenological approach to the social services. New York, NY: Wiley.

Bordes-Edgar, V., Arredondo, P., Robinson-Kurpius, S. R., \& Rund, J. (2011). A longitudinal analysis of Latina/o students' academic persistence. Journal of Hispanic Higher Education, 10, 358-368.

Collier, V. P., \& Thomas, W. P. (2004). The astounding effectiveness of dual language education for all. NABE Journal of Research and Practice, 2(1), 11-39.

Creswell, J. W. (2007). Qualitative inquiry and research design: Choosing among the five traditions (2nd ed.). Thousand Oaks, CA: Sage.

Crisp, G., Taggart, A., \& Nora, A. (2015). Undergraduate Latina/o students: A systematic review of research identifying factors contributing to academic success outcomes. Review of Educational Research, 85(2), 249-274.

Darder, A., Baltodano, M., \& Torres, R. (Eds.). (2003). The critical pedagogy reader. New York, NY: Routledge Falmer.

Delgado Bernal, D. (2002). Critical race theory, Latino critical theory, and critical raced-gendered epistemologies: Recognizing students of color as holders and creators of knowledge. Qualitative Inquiry, 8, 105-126.

Delgado Bernal, D. (2001). Learning and living pedagogies of the home: The Mestiza consciousness of Chicana students. International Journal of Qualitative Studies in Education, 14(5), 623-629.

Delgado Bernal, D., Burciaga, R., \& Flores Carmona, J. (Eds.) (2015). Chicana/Latina testimonios as pedagogical, methodological, and activist approaches to social justice. New York, NY: Routledge.

Delgado Bernal, D., Burciaga, R., Flores Carmona, J. (Eds.) (2012). Special issue: Chicana/Latina testimonios: Methodologies, pedagogies, and political urgency. Equity and Excellence in Education, 45(3). 363-372.

Delgado, R. \& Stefancic, J. (2001). Critical race theory: An introduction. New York, NY: New York University Press.

Dillman, D. (2000). Mail and internet surveys: The tailored method design (2nd ed.). New York, NY: John Wiley \& Sons.

Ernst-Slavitt, G., \& Wenger, K. J. (2006). Teaching in the margins: The multifaceted work and struggles of bilingual paraeducators. Anthropology and Education Quarterly, 37(1), 62-82.

Fry, R., \& Parker, K. (2012). Record of educational achievement. A Pew Research Center report. Washington, DC: Pew Research Center.

García, O. (2011). Bilingual education in the 21st century: A global perspective. Hoboken, NJ: Wiley-Blackwell. 
Gay, G. (2000). Culturally responsive teaching: Theory, research, and practice. New York, NY: Teachers College.

Genzuk M., \& Baca, R. (1998). The paraeducator-to-teacher pipeline. Education and Urban Society, 3(1), 73-78.

Genzuk, M., \& French, N. (2002). Recruiting paraeducators into teacher preparation programs: A remedy for the shortage of teachers. Washington, DC: American Association of Colleges for Teacher Education.

Genzuk, M., Lavadenz, M., \& Krashen, S. (1994). Paraeducators: A course for remedying the shortage of teachers for limited-English-proficient students. Journal of Educational Issues for Language Minority Students, 14, 211222.

Giroux, H. (2001). Theory and resistance in education: Towards a pedagogy for the opposition. Westport, CT: Bergin \& Garvey.

Giroux, H. A., \& McLaren, P. (1992). Writing from the margins: Geographies of identity, pedagogy, and power. Journal of Education, 174(1), 7-30.

Goldenberg, B. M. (2014). White teachers in urban classrooms: Embracing nonwhite students' cultural capital for better teaching and learning. Urban Education, 49(1), 111-144.

Herrera, S. (2016). Biography-driven culturally responsive teaching. New York, NY: Teachers College Press.

Herrera, S. G., Morales, A. R., Holmes, M., \& Herrera Terry, D. (2011). From remediation to acceleration: Recruiting, retaining, and graduating future culturally and linguistically diverse (CLD) educators. Journal of College Student Retention: Research, Theory \& Practice, 13(2), 229-250.

Holmes, M., Fanning, C., Morales, A., \& Herrera, S. (2012). Contextualizing the path to academic success: Culturally and linguistically diverse students gaining voice and agency in higher education. In Y. Kanno \& L. Harklau (Eds.), Linguistic minority students go to college: Preparation, access, and persistence (pp. 201-219). New York, NY: Routledge.

Howard, T. C., \& Navarro, O. (2016). Critical race theory 20 years later: Where do we go from here? Urban Education, 51(3), 253-273.

Irizarry, J. G. (2011). En la lucha: The struggles and triumphs of Latino/a preservice teachers. Teachers College Record, 113(12), 2804-2835.

Johnson, K., \& Williams, L. (2015). When treating all the kids the same is the real problem: Educational leadership and the $21^{\text {st }}$ century dilemma of difference. Thousand Oaks, CA: Corwin.

Katz, L., \& DaSilva Iddings, A. C. (2009). Race and technology in teacher education: Where is the access? In R. Kubota, \& A. Lin (Eds.) Race, culture, and identity in second language education (pp.130-147). New York, NY: Taylor Francis. 
Kanno, Y., \& Grosik, S. A. (2012). Immigrant English learners' transitions to university: Student challenges and institutional policies. In Y. Kanno \& L. Harklau, (Eds.) Linguistic minority students go to college: Preparation, access, and persistence (pp.138-157). New York, NY: Routledge.

Kohli, R., \& Solórzano, D. G. (2012). Teacher, please learn our names!: Racial microaggressions and the $\mathrm{K}-12$ classroom. Race, Ethnicity, and Education, 1-22. DOI: http://dx.doi.org/10.1080/13613324.2012.674026

Ladson-Billings, G. (1995). Toward a theory of culturally relevant pedagogy. American Educational Research Journal, 32(3), 465-491.

Lohfink, G., Morales, A., Shroyer, G., \& Yahnke, S. (2012). Growing effective CLD teachers for today's classrooms of CLD children. Action in Teacher Education, 34(1), 41-54.

Lucero, A. (2010). Dora's program: A constructively marginalized paraeducator and her developmental biliteracy program. Anthropology \& Education Quarterly, 41(2), 26-143.

Macedo, D. (2006). Literacies of power: What Americans are not allowed to know. Boulder, CO: Westview Press.

Maldonado, D. E. Z., Rhoads, R., \& Buenavista, T. L. (2005). The studentinitiated retention project: Theoretical contributions and the role of selfempowerment. American Educational Research Journal, 42(4), 605-638.

Maramba, D. C., \& Velasquez, P. (2012). Influences of the campus experience on the ethnic identity development of students of color. Education and Urban Society, 44(3), 294-317.

Matute-Bianchi, M. E. (1991). Situational ethnicity and patterns of school performance among immigrant and nonimmigrant Mexican-descent students. In J.U. Ogbu, Minority status, oppositional culture, and schooling (pp. 205-247). New York, NY: Routledge.

Moll, L., Amanti, C., Neff, D., \& Gonzalez, N. (1992). Funds of knowledge for teaching: Using a qualitative approach to connect homes and classrooms. Theory Into Practice, 31(2), 132-141.

Monzó, L. D., \& Rueda, R. S. (2001). Professional roles, caring, and scaffolds: Latino teachers' and paraeducators' interactions with Latino students. American Journal of Education, 109(4), 438-471.

Morales, A. (2016, February). Documenting professional development of Latina preservice teachers within a culturally responsive teacher education program. A paper presented at the American Association of Colleges for Teacher Education (AACTE), Las Vegas, NV.

Morales, A. (2011). Factors that foster Latina, English, language learner, nontraditional student resilience in higher education and their persistence in teacher education. Unpublished dissertation, Kansas State University, Manhattan, KS. 
Nieto, S., \& Bode, P. (2008). Affirming diversity: The sociopolitical context of multicultural education (5th ed.). New York, NY: Allyn \& Bacon.

Robnett, B. (1997). How long? How long: African-American women in the struggle for civil rights. New York, NY: Oxford University Press.

Romo, J. (2005). Border pedagogy from the inside out: An autoethnographic study. Journal of Latinos and Education, 4, 193-210.

Rodríguez, L. F., \& Oseguera, L. (2015). Our deliberate success: Recognizing what works for Latina/o students across the educational pipeline. Journal of Hispanic Higher Education, 14(2), 128-150.

Rueda, R., Genzuk, M., Baca, R., \& Hentschke, G. (1999). Latino paraeducators as teachers: Building on funds of knowledge to improve instruction. Final report prepared for the Center on Excellence, Diversity, and Education (CREDE), University of California, Santa Cruz.

Rueda, R., Monzó, L. D., \& Higareda, I. (2004). Appropriating the sociocultural resources of Latino paraeducators for effective instruction with Latino students: Promise and problems. Urban Education, 39(1), 52-90.

Santiago, D. A., \& Lopez, E. (2013). Growing what works: Lessons learned replicating promising practices for Latino student success. Washington, DC: Excelencia in Education.

Shroyer, G., Yahnke, S., Morales, A., Dunn, C., Lohfink, G., \& Espinoza, P. (Fall, 2009). Barriers and bridges to success: Factors for retention of nontraditional Mexican American students in teacher education. Enrollment Management Journal, 3(3), 40-73.

Simoniello, K. (1981). On investigating the attitudes toward achievement and success in eight professional U.S. Mexican women. International Journal of Chicano Studies Research, 12(1), 121-137.

Sleeter, C., \& Thao, Y. (2007). Diversifying the teaching force. Teacher Education Quarterly, 34(4), 3-8.

Stanton-Salazar, R. D. (2011). A social capital framework for the study of institutional agents and their role in the empowerment of low-status students and youth. Youth \& Society, 43(3), 1066-1109.

Solórzano, D. G., \& Delgado Bernal, D. (2001). Examining transformational resistance through a critical race and LatCrit theory framework: Chicana and Chicano students in an urban context. Urban Education, 36, 308-342.

Valenzuela, A. (1999). Subtractive Schooling: U.S.-Mexican youth and the politics of caring. Albany, NY: SUNY Press.

Varghese, M. M. (2012). A linguistic minority student's discursive framing of agency and structure. In Y. Kanno \& L. Harklau (Eds.), Linguistic minority students go to college: Preparation, access, and persistence (pp. 201219). New York, NY: Routledge. 
Villegas, A. M., \& Clewell, B. C. (1998). Increasing teacher diversity by tapping the paraprofessional pool. Theory into Practice, 37(2), 1-9.

Villegas, A. M., \& Lucas, T. (2002). Educating culturally responsive teachers: A coherent approach. Albany, NY: State University of New York.

Walqui, A., \& van Lier, L. (2010). Scaffolding the academic success of adolescent English language learners: A pedagogy of promise. San Francisco, CA: WestEd.

Wink, J. (2005). Critical pedagogy: Notes from the real world. San Francisco, CA: Pearson.

Woodson, C. G. (1933). The miseducation of the Negro. Washington, DC: The Associated Publishers.

\section{Author Contact}

Amanda R. Morales, PhD: morales@ksu.edu

University of Nebraska-Lincoln, 1400 R Street, Lincoln, Nebraska 68588, USA

M. Gail Shrover, PhD: gshroyer@ksu.edu

Kansas State University, Manhattan, Kansas 66506, USA 